\title{
The Effect of Communication Change on Long-term Reductions in Child Exposure to Conflict: Impact of the Promoting Strong African American Families (ProSAAF) Program
}

\author{
STEVEN R. H. BEACH* \\ ALLEN W. BARTON* \\ MAN KIT LEI* \\ GENE H. BRODY* \\ STEVEN M. KOGAN* \\ TERA R. HURT ${ }^{\dagger}$ \\ FRANK D. FINCHAM \\ SCOTT M. STANLEY
}

\begin{abstract}
African American couples $(\mathrm{n}=331)$ with children, $89 \%$ of whom were married, were assigned to either (a) a culturally sensitive couple-and parenting-enhancement program (ProSAAF) or (b) an information-only control condition in which couples received self-help materials. Husbands averaged 41 years of age and wives averaged 39 years. We found significant effects of program participation in the short term on couple communication, which was targeted by the intervention, as well as over the long term, on self-reported arguing in front of children. Long-term parenting outcomes were fully mediated by changes in communication for wives, but not for husbands. For husbands, positive change depended on amount of wife reported change. We conclude that wives' changes in communication from baseline to posttest may be more pivotal for the couples' long-term experience of decreased arguing in front of children than are husbands' changes, with wives' changes leading to changes in both partners' reports of arguments in front of children.
\end{abstract}

Keywords: Co-parenting; Marriage; Communication; Conflict

Fam Proc 53:580-595, 2014

$\mathrm{I}^{\mathrm{n}}$ nterparental dynamics can have a substantial impact on the quality of co-parenting and effective parenting practices in general (Jones, Zalot, Foster, Sterrett, \& Chester, 2007; Porter \& O'Leary, 1980). For instance, both couple conflict (e.g., Krishnakumar \& Buehler, 2000) and couple relationship quality significantly influence effective parenting (Cummings, Goeke-Morey, \& Graham, 2002). Conflict witnessed by the child is a particularly

\footnotetext{
*Center for Family Research, University of Georgia, Athens, GA.

${ }^{\dagger}$ Human Development and Family Studies, Iowa State University, Ames, IA.

FSU Family Institute, Florida State University, Tallahassee, FL.

${ }^{\S}$ Psychology, University of Denver, Denver, CO.

Correspondence concerning this article should be addressed to Steven R. H. Beach, Center for Family Research, University of Georgia, 508 Boyd GSRC, Athens, GA 30602. E-mail: srhbeach@uga.edu.

This article was supported in part by grant \#1021RR274307 from ACF awarded to Steven R. H. Beach. The last author of this report co-owns a business that develops, refines, and sells the PREP curriculum upon which parts of the intervention tested here are based. Tera R. Jordan publishes scholarly work using her maiden name Tera R. Hurt.
} 
problematic co-parenting dynamic (e.g., Grych, 2005), with the potential to influence a range of child outcomes (Jones, Shaffer, Forehand, Brody, \& Armistead, 2003). However, instances of overt interparental conflict are less likely to occur when parents utilize effective communication strategies, hence supporting a focus on parents' listening and communication skills to promote family well-being (Jordan, Stanley, \& Markman, 1999).

This study provides an initial examination of the efficacy of a newly developed skillsbased program for African American parents of preadolescent and adolescent youth, the Promoting Strong African American Families (ProSAAF) program. This program is designed to promote positive co-parenting outcomes by targeting couple communication and felt efficacy. This study examines short-term effects on couple communication and relationship efficacy and longer term (i.e., 2-year) effects on co-parenting in the domain of arguing in front of children. In addition, changes in self-reports of effective couple communication are examined as possible mechanisms through which the intervention impacts co-parenting dimensions.

Because observational and intervention studies with African American families focus overwhelmingly on youth living in single-parent households (Jones et al., 2007), the choice to focus on parent dyads requires some explanation. Extant research creates the impression that the modal living arrangement for African American children and youth is a household with a single mother and no father or father figure. However, more than half of African American youth live in a household with a biological father or a father figure, such as a stepfather or a mother's romantic partner (Bzostek, 2008), who directly or indirectly influences parenting. Not surprisingly, positive involvement in children's and youths' lives from both residential biological fathers and father figures plays a significant role in youth development (Black, Dubowitz, \& Starr, 1999; Jayakody \& Kalil, 2002; Jordan \& Lewis, 2005). Among African American youth, father involvement is positively associated with academic achievement, self-esteem, and life satisfaction and is linked negatively with emotional and behavioral problems, substance use, and risky sexual behavior (Coley, 2003; Jordan \& Lewis, 2005; Paschall, Ringwalt, \& Flewelling, 2003; Salem, Zimmerman, \& Notaro, 1998).

This study also diverges from previous research on co-parenting interventions by focusing on parents of preadolescent and adolescent children. Although there are good reasons to offer co-parenting programs to new parents (the target population of most previous co-parenting interventions), high quality co-parenting may be particularly importantand the benefits of reduced arguments in front of children may be particularly salientwhen parents are dealing with preadolescents and adolescents. Adolescence is a time of dramatic physiological, cognitive, emotional, and social changes in response to pubertal events, maturational processes, and school transitions (Eccles et al., 1993; Ge, Brody, Conger, Simons, \& Murry, 2002) requiring parents to work together on a number of issues. For many African Americans, early adolescence is also accompanied by increased awareness of racial stratification, experience with discrimination (Brody, Chen, et al., 2006), awareness of economic difficulty, and the need to cope with scarce resources (Trzcinski, 2002). When parents are unable to work together effectively, this may place youth at risk for compromised emotional and behavioral self-regulation, affecting their engagement with school and other conventional pursuits, potentially increasing their vulnerability to school failure, internalizing and externalizing problems, substance use, and the early onset of sexual activity (Brody \& Flor, 1998; Brody, Stoneman, Flor, \& McCrary, 1994; Conger, Ge, Elder, \& Lorenz, 1994; Mayhew \& Lempers, 1998; Simmons, Burgeson, Carlton-Ford, \& Blyth, 1987). In sum, the changes associated with adolescence can challenge both youth and their caregivers and, for optimal outcomes, require caregivers to enact effective co-parenting practices such as reducing or avoiding arguments in front of the adolescent. 
Unfortunately, family centered programs for African American youth have often neglected or failed to recruit fathers or father figures. Hence, one reason that co-parenting has received limited attention is the potential obstacle of getting fathers involved, particularly when programs are delivered using group formats in community or school settings. Typically this has led to recruiting primary caregivers of youth-most often mothers (Cohen \& Linton, 1995; Dishion, Kavanagh, Schneiger, Nelson, \& Kaufman, 2002)—with fathers left out of the equation. The challenge is significant, as men in general and African American men in particular are often reluctant to participate in family centered programs offered in the community or at school (Brandon, Higgins, Pierce, Tandy, \& Sileo, 2009; Hurt et al., 2012; Pruett, Cowan, Cowan, \& Pruett, 2009; Roy \& Dyson, 2010; Spoth, Redmond, \& Shin, 1998). The dilemma becomes self-fulfilling as group meeting without fathers may reinforce the message that the meetings are not for fathers. In short, existing interventions for African American youth are not well designed to recruit fathers or involve them in the change program, limiting their ability to initiate change in couple communication, or to influence mothers' perception of their co-parenting efficacy. This potentially leaves mothers feeling unsupported by fathers in the critical domain of parenting. At the same time, fathers are left unengaged in the parenting change process, potentially sending the wrong message regarding their importance in childrearing.

Optimal progress in the field of prevention requires an understanding of the change mechanisms that account for outcomes of interest. However, there has been little attempt to examine couple processes and whether these function as a mechanism through which intervention produces change in destructive patterns such as arguing in front of children. We examine mediational models to test the hypothesis that intervention materials influence arguments in front of children by altering patterns of communication around potential areas of conflict in the co-parenting dyad. If interparental communication is a mechanism for enhancing long-term co-parenting outcomes, it opens the way for greater inclusion of such material in a range of prevention programs. Because a variety of efficacious programs have been developed targeting couple and marital functioning (Hawkins, Blanchard, Baldwin, \& Fawcett, 2008), there is strong potential to enhance parenting programs and strengthen the co-parenting relationship in a variety of ways. It is noteworthy that, despite robust findings linking marital conflict to child maladjustment (e.g., Cummings \& Davies, 2002), documentation of the impact of couple-focused programs on co-parenting among low income and minority participants is rare (Hawkins \& Fackrell, 2010), with some tests showing no such impacts (Wood, Moore, Clarkwest, Killewald, \& Monahan, 2012), pointing to the need for additional information in this context.

Given the focus on mothers in parenting interventions, potential gender differences are of particular interest in evaluating co-parenting interventions. Previous interventions focusing on marital relationship outcomes among African American couples have reported differing effects for husbands and wives (Beach et al., 2011), but overall effects of marital enhancement programs tend to be similar for husbands and wives (Hawkins et al., 2008). Parenting programs have been better able to recruit mothers, suggesting that mothers may be more readily engaged and responsive to parenting interventions yet prior literature suggests that the link between couple functioning and parenting behavior may be stronger for fathers than mothers (Coiro \& Emery, 1998). In the current investigation, we therefore examine possible gender differences.

\section{Study Aims and Hypotheses}

ProSAAF was designed to address couple and co-caregiving relationship processes relevant to raising preadolescent and adolescent youth in African American families. The focus of the intervention (described further below) was to enhance co-parenting, 
particularly listening and reduced conflict around issues related to youth behavior and youth development. This study examines changes in interparental behavior and parenting outcomes for African American married or cohabiting couples randomly assigned to the ProSAAF program or a control condition. In contrast to extant programs for African Americans, the ProSAAF implementation model is designed to achieve high rates of participation among fathers and father figures by offering a 6 -week program in the family home and encouraging participation by both parent figures.

We tested three main hypotheses:

1. Participating in the ProSAAF intervention will increase use of effective communication strategies immediately following the intervention.

2. Participating in the ProSAAF intervention will be associated with long-term improvement in self-reported co-parenting quality as evidenced by reduced arguing in front of the target youth.

3. Changes in self-reported, effective communication strategies will mediate the effect of the intervention on reduced arguing in front of the target youth.

Although we did not hypothesize a direction of effect for gender differences, dyadic analyses allowed us to examine the extent to which differential impact of the intervention on one gender partially or fully mediated the impact of treatment on the other.

\section{METHOD}

\section{Design}

The study was a randomized control trial with two groups (treatment and control) followed over a time period of approximately 2 years. All procedures were approved by the institutional review board.

\section{Participants}

Participants in the study were heterosexual couples with a preadolescent or adolescent child self-identifying as African American. For ease of communication, we refer to women as "wives" and men as "husbands" throughout the manuscript. To maximize generalizability of findings regarding the effects on co-parenting, a wide range of target youth ages were allowed, spanning preadolescence through adolescence and high school (range 9-17). In total, pretest data were collected from 331 families who met all study criteria (described below). Of the randomized sample, 89\% were married $(n=296)$, with an average marital duration of 12 years (range 0-37 years). Husbands' mean age was 41 (range 25-71) and wives' mean age was 39 (range 22-68). Although only one partner in the couple was required to be African American, the vast majority of the men (98\%) and women (98\%) in the sample reported being African American. Men's mean level of education was some college or trade school (ranging from not graduating from high school to holding a Doctorate or professional degree) and women's mean level of education was trade school diploma or Associate's Arts Degree (ranging from not graduating from high school to Doctorate or professional degree). The majority of men (89.6\%) and women $(79.5 \%)$ reported full- or part-time employment. Mean monthly income from primary jobs was $\$ 1606$ (range $\$ 1-\$ 15,000$ ) for men and $\$ 1677$ (range $\$ 0-\$ 14,000$ ) for women. For the target adolescent, the mean age was 12 at enrollment in the program and mean grade at enrollment was seventh grade (range fourth grade-high school). Total number of children residing in the home ranged from 1 to 10 , with a mean of 2 children residing in the home. 


\section{Procedures}

Couples were recruited to the project through referrals and advertisements distributed through a variety of outlets (e.g., churches, community fairs, radio shows, newspapers, local businesses). A total of 397 families inquired about participating in the study and were assessed for eligibility. To be eligible, individuals had to be an African American adult at least 21 years of age with a mate (of any age or any race) also willing to participate. The couple must have been married or planning to marry with a definite date in mind, living together, and residing with an adolescent child 9 to 17 years of age. The 9- to 17-year-old adolescent also had to be willing to answer questions about his or her experiences (analyses of youth data will be presented in subsequent studies). Finally, couples had to be willing to spend 6 weeks engaged in an in-home educational program if they were randomly assigned to the intervention condition and not planning to move out of the study area.

Block randomization was performed to ensure comparability between couples in treatment and control groups. For pretest measures, a team of two interviewers visited couples' homes and read all pretest questions to participants to ensure appropriate pace of the interview and prevent any challenges with functional illiteracy. Approximately 3 months after pretest, treatment and control groups completed posttest measures using audio computer-assisted self-interviewing software installed on laptop computers. Long-term followup data collection, which occurred 24 months following the pretest, was conducted via a secure online website or mailed paper copy (where required).

\section{Retention}

Of the 331 families initially assessed at pretest, we had contact with 288 families (91\% married) at postassessment and 279 families (86\% married) at 24 -month follow-up. Families left the study for various reasons including moving, illness, and leaving no forwarding address. Full data on progress through the study and the number retained at each assessment time and in each treatment condition can be found in the CONSORT diagram below (Figure 1).

\section{ProSAAF Program Implementation}

\section{Content and delivery}

The ProSAAF program was designed to enhance couple relationship processes as a means of facilitating competence-promoting parenting practices among African American couples raising preadolescent or adolescent youth and to reduce ineffective conflict occurring in front of youth. Program content was based on two existing efficacious programs, one focused on couple functioning (ProSAAM; Beach et al., 2011) and another focused on parenting processes and youth competencies with rural African Americans (SAAF; Brody, Murry, et al., 2006). Trained facilitators visited the couple's home for six consecutive weeks and facilitated a 90-minute session with co-parenting adults.

For each of the six sessions, the facilitator guided couples through video instruction and modeling, structured activities, and specific topics for discussion. Content addressed in each session included: (1) Communication; (2) Expectations, Ground rules, Listening, Support, and Conflict Resolution; (3) Problem-solving and Joint Activities; (4) Supporting Children and No-Nonsense Parenting; (5) Everyday Parenting, Helping Children Exceed In School, Protecting Against Dangerous Behavior; and (6) Encouraging Ethnic Pride and Staying Connected with Children. Early content focused on the couple's relationship, and provided a foundation for discussion of later content focused on co-parenting. The ProSAAF implementation model included multiple components designed to achieve high 


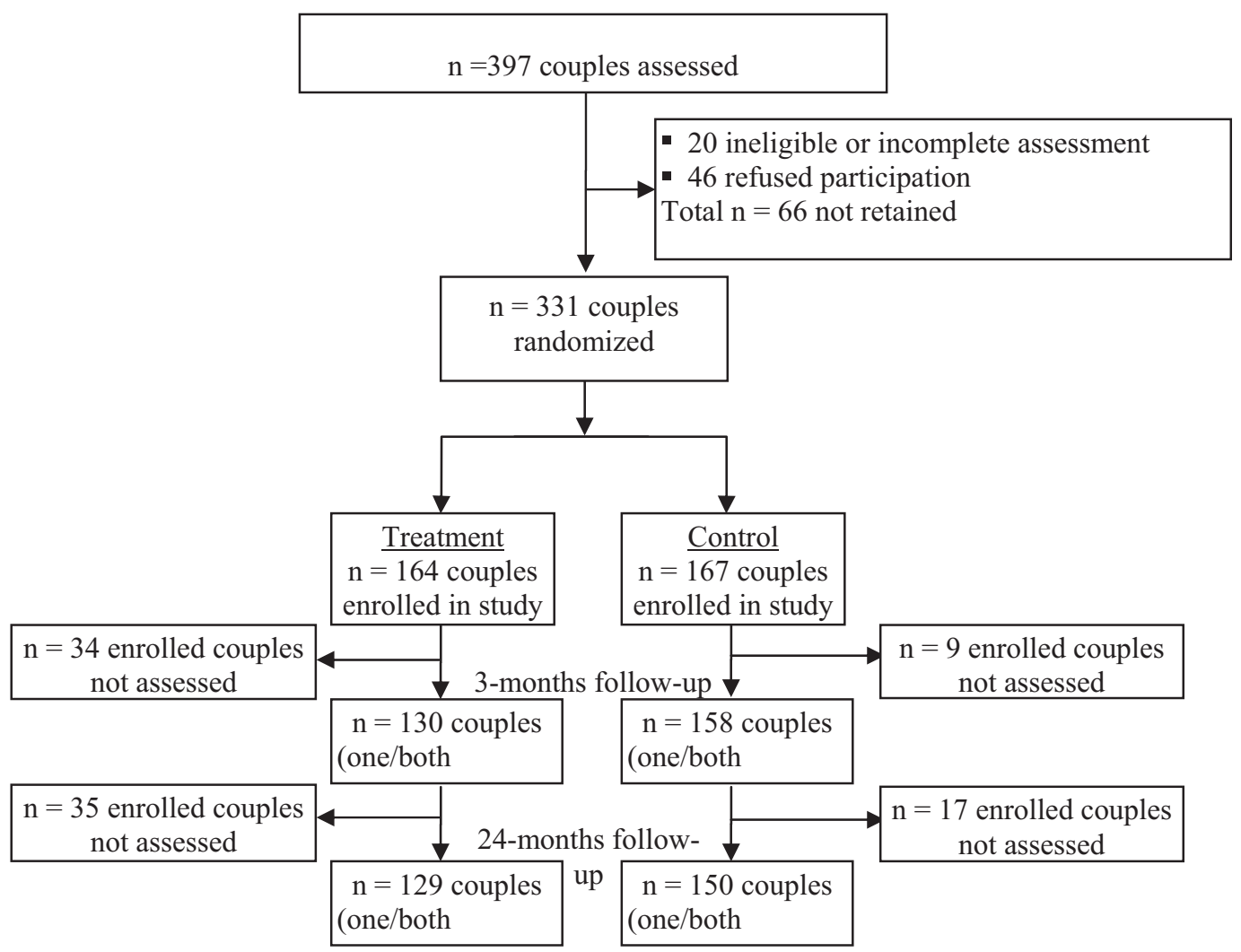

FiguRE 1. CONSORT Flow Chart: Diagram of Flow of Couples from Recruitment Through Retention.

rates of participation and retention among fathers and father figures (e.g., refining engagement protocols for targeting males, home-based implementation model).

\section{Control group}

Couples in the control group were assessed on the same schedule as those in the intervention group, thereby controlling for effects of repeated measurement, maturation, individual differences, and external social changes. In addition, couples in the control group were provided the book "12 Hours To A Great Marriage" (Markman, Stanley, Blumberg, Jenkins, \& Whiteley, 2004) at the conclusion of their baseline assessment. This popular guidebook provided positive reasons for enhancing marriage, guidelines and examples of communication and problem-solving strategies, exercises that could be implemented by individuals and couples to enhance their relationship, and suggestions for enhancing positive aspects of the marital relationship.

\section{Attendance}

Men and women in the intervention group attended, on average, slightly more than five of the sessions. Three quarters of participants (76\%) attended all six sessions. Analyses are conducted on the intent to treat sample and include all participants.

\section{Measures}

Partners were assessed on standard demographic measures including age, income, education, and family composition as well as target measures of outcome (i.e., effective 
communication and co-parenting) and baseline relationship functioning (i.e., marital satisfaction and marital instability).

\section{Effective communication}

Participant reports of effective communication were assessed using a four-item version of the Relationship Efficacy Measure (REM; Bradbury, 1989) and an eight-item version of the Communication Skills Test (CST; Jenkins \& Saiz, 1995). All items loaded on a single factor, with loadings ranging from .4 to .85 for both husbands and wives. Accordingly, mean scores were computed for each measure, standardized, and then averaged together to create a single score. The four items from the REM assessed the degree to which spouses believe they have the ability to resolve conflicts with their partners (e.g., "I am able to do the things needed to settle our conflicts"; husbands: $\alpha=.67$ [pretest] and $=.74$ [posttest]; wives: $\alpha=.74$ [pretest] and $=.80$ posttest]). The eight items from the CST assessed effective communication patterns within the couple (e.g., "when discussing an issue, my mate and I both take responsibility to keep us on track", "when our discussions begin to get out of hand, we agree to stop them and talk later"; husbands: $\alpha=.84$ [pretest] and $=.88$ [posttest]; wives: $\alpha=.85$ [pretest] and $=.89$ [posttest]). Higher scores reflected greater effective communication.

\section{Arguing in front of target youth}

Participants' experience with co-parenting was assessed using five items from the O'Leary Porter scale (Porter \& O'Leary, 1980). Factor analysis indicated that the resulting scale reflected a single construct capturing tendency to disagree about discipline, family roles, and each other's personal characteristics in front of the child (e.g., "How often do you and your mate disagree over disciplining in front of [target adolescent's name]", "In every relationship there are arguments. How often do the arguments between you and your mate happen in front of [target adolescent's name]"; husbands: $\alpha=.80$ [pretest] and $=.84$ [2-year follow-up]; wives: $\alpha=.84$ [pretest] and $=.82$ [2-year follow-up]). Higher scores reflected less arguing in front of the child.

\section{Marital satisfaction}

The six-item Quality of Marriage Index (QMI) is a unidimensional index that measures global perceptions of marital satisfaction (Norton, 1983) and has been widely recommended for use with community samples. Low scores indicate a more negative evaluation. A sample item is, "Our relationship is strong." Internal consistency in this study was high (husbands: $\alpha=.93$; wives: $\alpha=.95$ ).

\section{Marital instability}

The Marital Status Inventory (MSI; Weiss \& Cerreto, 1980) was used to index degree of baseline instability in the dyad. The MSI has been used to predict probability of divorce and other forms of relationship instability, with respondents rating items (e.g., "My spouse and I have separated") as true or false. Split-half reliability has been estimated at .86 (Crane \& Mead, 1980), with high internal consistency observed in current study (husbands: $\alpha=.84$; wives: $\alpha=.87$ ). The MSI has been shown to be valid in assessing high marital distress and divorce potential (Whiting \& Crane, 2003).

\section{Plan of Analysis}

We investigated changes following participation in the program using dyadic analytic techniques, including the conventional actor-partner interdependence model (APIM; Kenny, Kashy, \& Cook, 2006). The key advantage of this approach is that it controls for 
the nonindependence of husband and wife reports and allows estimation of the impact of one partner's report on the other's later report (i.e., partner effects). To provide an additional window on partner effects, we also examined nonrecursive (i.e., reciprocal) effects between outcomes for husbands and wives. In these models, bidirectional effects between spouses are examined at long-term follow-up. Finally, we tested communication change as a possible mediator of intervention effects on reduced exposure to parental conflict.

APIM assumes that the data from two members of a dyad are not independent and, hence, treats the couple as the unit of analysis. Doing so allows for the simultaneous estimation of actor and partner effects. Because analyses are for heterosexual couples, the APIM was conducted for distinguishable dyads within a structural equation modeling (SEM) framework (via Mplus Version 6; Muthen \& Muthen, 2010). The APIM is a fully saturated model, meaning that model fit statistics are unavailable. Models can often be reduced, however, by excluding nonsignificant paths or by implementing parameter constraints (described further below). Hence, when appropriate, model fit is evaluated using the criteria of CFI and RMSEA as proposed by Hu and Bentler (1999). In addition, effect sizes are estimated using the metric provided by MacCallum, Browne, and Cai (2006), " $\delta$ " providing an index comparable to Cohen's d.

Both differences in actor and partner effects, as well as gender differences in effects, can be tested via a Wald test of parameter constraints (paths can be tested individually or collectively via an omnibus test). If the Wald test indicates that paths or sets of paths do not differ significantly from one another, those paths may be assumed to be nonsignificantly different. Wald tests for gender differences are given priority in all models.

In our analyses, we first tested equivalence of intervention and control groups at pretreatment. We next examined impact of intervention on posttreatment change in intervention targeted constructs using an APIM framework. We explored gender differences in impact using model constraints and by testing relative strength of mediation of intervention effects on each partner by way of impact on the other. Finally, we examined the role of communication change as a mediator of treatment effects on long-term change in arguing in front of the target youth.

\section{RESULTS}

\section{Equivalence of Treatment and Control Groups}

Equivalency analyses were conducted to verify similarity of couples in treatment and control conditions. No demographic differences were observed between conditions for individual- or couple-level characteristics, such as education, marital status, age of adults or target child, pretest communication, co-parenting, satisfaction, ethnicity, or marital stability.

\section{Program Effects on Communication at Short-term Follow-up}

We first tested the effect of the ProSAAF intervention on communication at posttest (3 months after pretest) within an APIM framework. The ProSAAF intervention had a significant positive effect on use of effective communication and enhanced relationship efficacy for both husbands $(\beta=.152, p=.000, \delta=.099)$ and wives $(\beta=.268, p=.000$, $\delta=.203$ ), supporting hypothesis 1 . Thus, ProSAAF participants showed improved effective communication at posttest compared to participants who did not receive the program.

As regards gender differences, constraining the intervention effect to be the same for husbands and wives resulted in a significant deterioration in model fit, $\chi^{2}(1)=5.293, p=$ .021 , thus indicating a significant gender effect with regard to intervention impact. Specifically, wives in the ProSAAF intervention group reported more pronounced improvements 
in communication and relationship efficacy following participation in the program compared to the improvement reported by husbands. No gender differences emerged in actor $(p=.158)$ or partner $(p=.235)$ effects in effective communication over time.

\section{Examination of nonrecursive (reciprocal) effects}

To further examine the impact of gender differences on each partner's outcomes, we tested models with reciprocal effects at posttest. Accordingly, no cross-lag effects could be included without underspecifying the model. Consistent with the APIM analysis, the effect of wives' posttest communication on husbands' posttest communication was significant $(\beta=.166, p=.026, \delta=.061)$. However, the effect of husbands' communication on wives was marginal $(\beta=.124, p=.080, \delta=.042)$. There was a significant indirect effect from intervention on husband outcomes by way of wife changes in effective communication (Indirect Effect $=.045 ; 95 \%$ CI [.002, .087]), representing 29\% of the total effect of intervention on husband outcomes. In contrast, there was no significant indirect effect of intervention on wife outcomes by way of husband changes (Indirect Effect $=.019 ; 95 \%$ CI $[-.008, .045])$. Therefore, the analyses indicated a greater impact of the intervention on wives' communication relative to the impact on husbands' communication, with program effects on wives having greater impact on husbands than vice versa.

\section{Program Effects on Arguing in Front of Target Youth at Long-term Follow-up}

To address hypothesis 2, we again used the APIM analytic framework to examine the impact of the intervention on each partner's experience of arguing in front of target youth at 24 months after baseline assessment. After taking into account both actor and partner reported levels of arguing in front of target youth at pretest, wives in the intervention reported significantly reduced levels at long-term follow-up compared to those in the control condition $(\beta=.128, p=.007, \delta=.078)$. Husbands in the intervention also demonstrated reduced levels $(\beta=.098, p=.034, \delta=.061)$. Thus, Hypothesis 2 was supported, indicating that the program had the intended impact on each partner's experience of arguing in front of target youth.

To test for gender differences in effect on arguing in front of target youth, we systematically constrained effects to be the same. Despite nominal differences in intervention effects for husbands and wives, gender differences could be constrained to be equal without deterioration in model fit, $\chi^{2}(1)=1.914, p=.384$, indicating no significant gender difference in the positive and significant intervention effect on the long-term outcome of arguing in front of target youth.

\section{Examination of nonrecursive (reciprocal) effects}

Again, to further examine gender differences in effects of intervention and to directly examine the hypothesis that intervention effects on wives might be more consequential for long-term outcomes of husbands than vice versa, we examined a model in which reciprocal pathways were allowed between husband and wife reports of arguing in front of target youth (see Figure 2). As before, to avoid an under-identified model, the cross-lagged (i.e., partner effects pathways) were omitted. The effect of change in wife report of arguing in front of target youth on husband report was significant $(\beta=.525, p=.000, \delta=.159)$ as was the effect of change in husband report of arguing in front of target youth on wife report $(\beta=.298, p=.000, \delta=.062)$. These patterns result in substantially different estimates of the fraction of the intervention effect that is accounted for by partner changes for husbands and wives. As reported in Table 1, for husband outcomes, 68\% of the effect of intervention was attributable to the indirect effect from intervention through wives' change in report of arguing in front of target youth, reflecting a significant indirect 


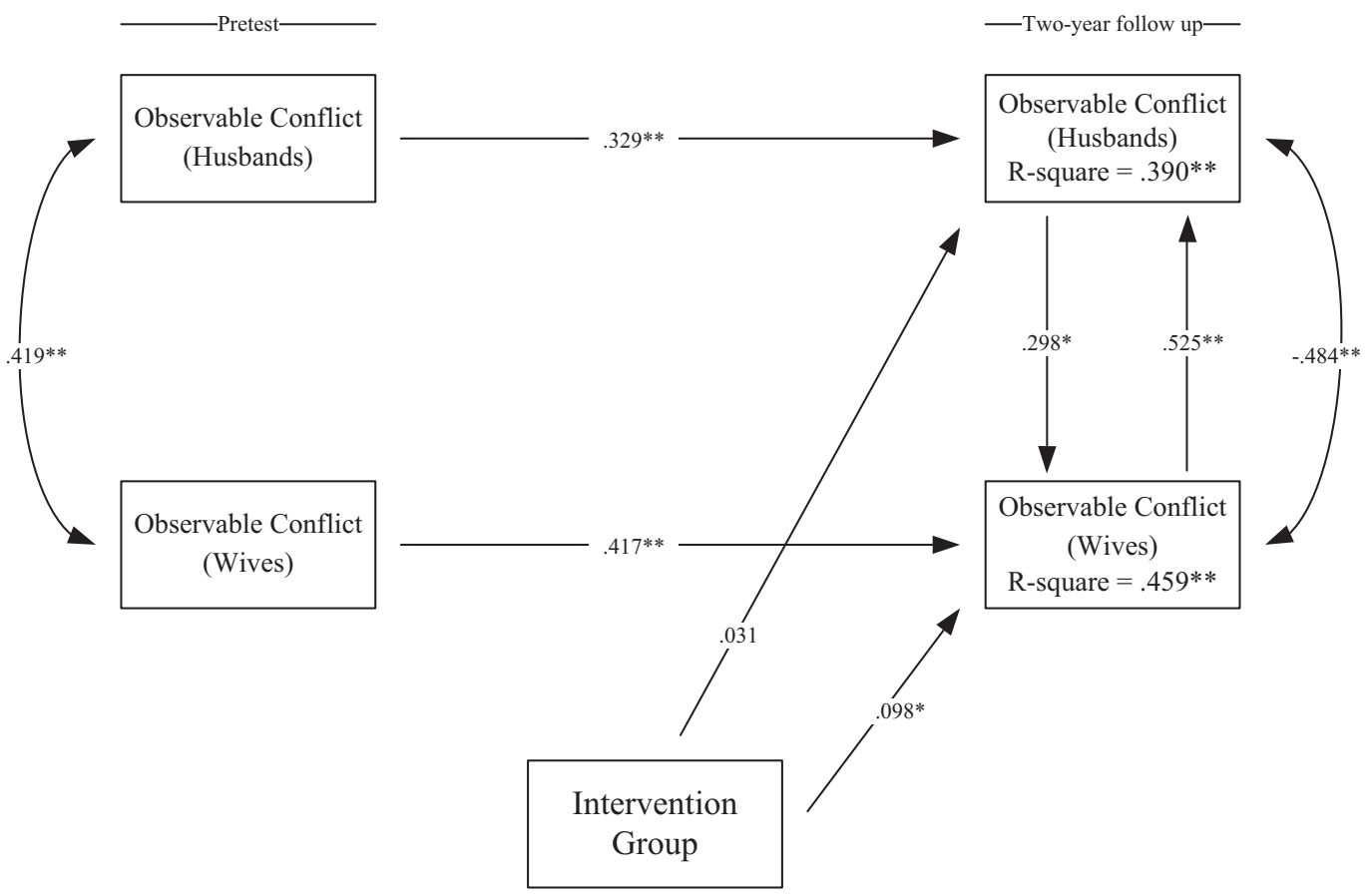

Figure 2. Effect of Intervention on Change in Conflict in Front of the Target Youth: Alternative Specification of the Actor-Partner Interdependence Model (APIM) to Examine Reciprocal Effects.

Note. Unconstrained baseline model: $\chi^{2}(2, N=331)=1.914, p=.384 . \mathrm{RMSEA}=.000$, and $\mathrm{CFI}=1.000$. Path coefficients are standardized parameter estimates. ${ }^{\dagger} p \leq .10 ;{ }^{*} p \leq .05 ;{ }^{* *} p \leq .01$ (two-tailed tests).

TABLE 1

Significance of Indirect Effects of Intervention Through Partner Reports on Conflict in Front of the Target Youth for Husbands and Wives ( $\mathrm{N}=331$ Couples)

\begin{tabular}{lccc} 
Paths & Total effect & Indirect effect & $\begin{array}{c}\text { variance for } \\
\text { mediator, \% }\end{array}$ \\
\hline $\begin{array}{c}\text { Path 1: Intervention } \rightarrow \text { Observable } \\
\text { Conflict (wives) } \rightarrow \text { Observable Conflict } \\
\text { (husbands) }\end{array}$ & $.098^{*}[.001 ; .195]$ & $.067^{*}[.007 ; .126]$ & 68.37 \\
$\begin{array}{c}\text { Path 2: Intervention } \rightarrow \text { Observable } \\
\text { Conflict (husbands) } \rightarrow \text { Observable }\end{array}$ & $.128^{* *}[.037 ; .218]$ & $.029[-.010 ; .068]$ & 22.66 \\
$\quad$ Conflict (wives) & & & \\
\hline
\end{tabular}

Note. The values presented are standardized parameters. Bootstrapping with 1,000 replications. ${ }^{* *} p \leq .01$ (two-tailed test); ${ }^{*} p \leq .05$ (two-tailed test).

pathway to husband parenting outcomes. Conversely, the indirect effect of intervention on wife outcomes through husband changes was nonsignificant. Thus, similar to effects on short-term communication, intervention effects on long-term reports of arguing in front of target youth indicated significantly greater indirect effects through wives, with program effects on wives having greater impact on husbands than vice versa. 


\section{Mediated Impact of Effective Communication on Arguing in Front of Target Youth}

To directly test the hypothesized mechanism of program effects on parenting outcomes, we examined a model in which changes in marital communication mediated program effects on arguing in front of target youth. We examined potential actor effect pathways of influence from intervention to each partner's report of arguing in front of target youth at long-term follow-up (i.e., 24 months after baseline assessment). Pathways through partner effects were not examined because partner effects were not significant, precluding significant mediation via this route. In keeping with the previously described gender differences, long-term intervention effects on arguing in front of target youth were constrained to be equal, but we allowed other effects to vary by gender. The resulting pattern of effects is portrayed in Figure 3 below.

To test hypothesis 3 , that changes in communication mediate program effects on arguing in front of target youth, we examined the significance of the mediated effect for husbands and wives using actor effects as the pathway of interest in each case. Specifically, using a bootstrapping procedure to develop a distribution-free test of indirect effects (number of bootstrap samples $=1,000$ ), there was a significant indirect effect of intervention on arguing in front of target youth transmitted through effective communication for wives (Indirect Effect $=.064,95 \%$ CI $[.027, .102]$ ), but not for husbands (Indirect Effect $=.017$, 95\% CI $[-.008, .043])$. Intervention targeted change in marital communication accounted

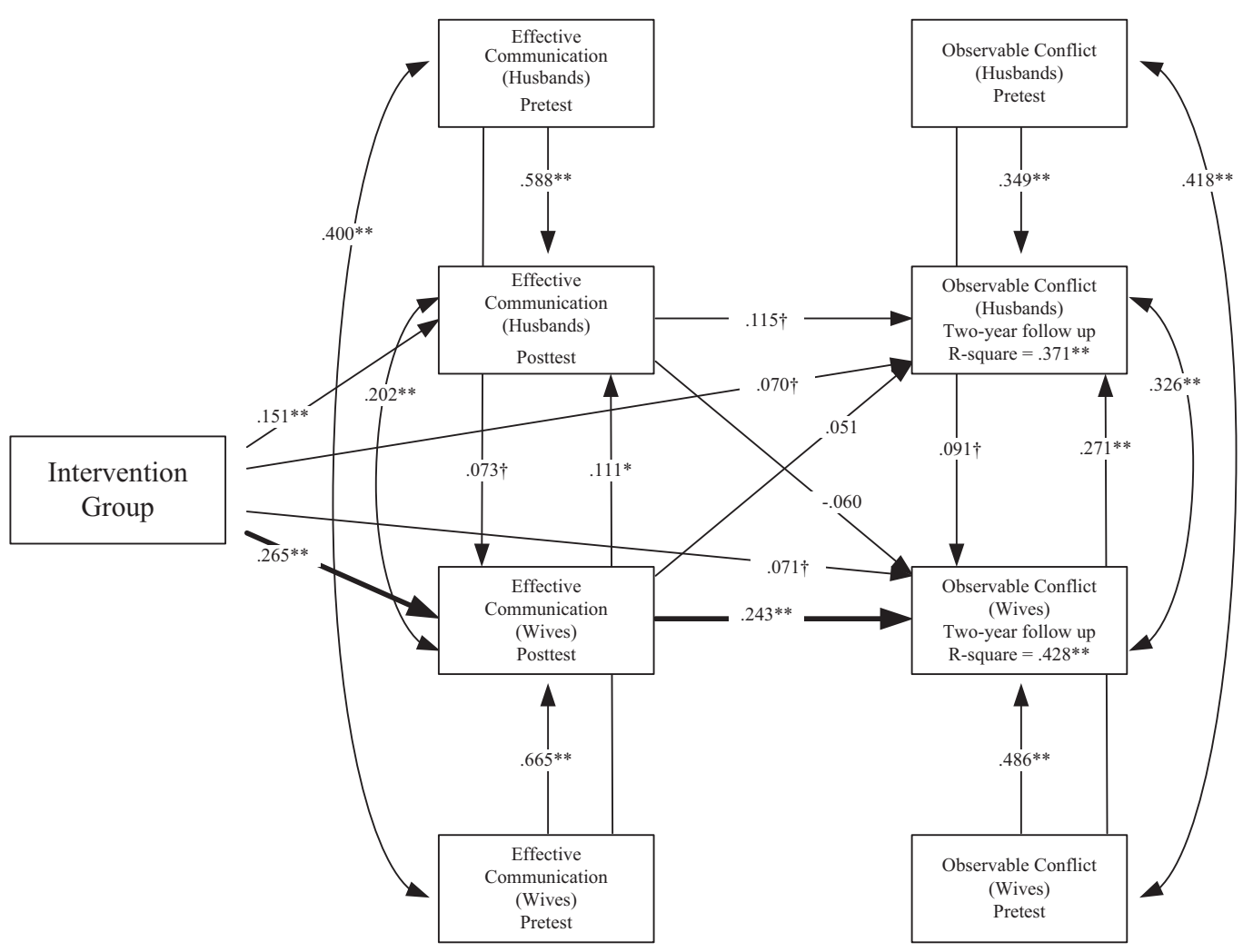

FiguRE 3. Effective Communication as a Mediator of the Effect of Intervention on Conflict in Front of the Target Youth. Note. Constrained baseline model (intervention effects on conflict in front of the target youth fixed across genders): $\chi^{2}=13.548, d f=12, p=.331$. RMSEA $=.020$, and CFI $=.998$.

Values are standardized parameter estimate. $N=331 .{ }^{*} p \leq .05 ; * * \leq .01$ (two-tailed tests). 
for $50.8 \%$ of the intervention effect on wives' report of arguing in front of target youth, but only $16.8 \%$ of the intervention effect on report of arguing in front of target youth for husbands (see Table 2).

\section{DISCUSSION}

The ProSAAF program was designed to engage parents in committed relationships, help them change key communication practices, and thereby enable them to make changes in their co-parenting practices, particularly by reducing ineffective conflict in front of youth in the home. The program was skilled-based, in the tradition of the PREP (Markman, Stanley, \& Blumberg, 2010) and the SAAF (Brody, Murry, et al., 2006) programs, but was designed for in-home delivery to increase participation by both partners. The in-home format we adopted allowed for successful recruitment of fathers as well as mothers, and it allowed for successful retention of both partners across six waves of intervention. This study does not provide a direct test of alternative strategies for engaging fathers, but the intervention design was effective for engaging families in this study.

We anticipated that the program's focus on enhancing dyadic communication would prove to be a key mechanism accounting for its long-term effects on changes in parenting practices, particularly in relation to arguing or engaging in other forms of conflict in front of the child. We found rapid, significant effects of program participation on parent communication, which was targeted by the intervention, as well as over the long term on self-reported arguing in front of target youth. Thus, short-term changes in reported communication quality between partners were associated with perceived long-term changes in the ability of co-parents to inhibit negative communication around their child(ren).

The asymmetrical pattern of mediation observed for husbands and wives is important for several reasons. We expected that intervention effects on changes in arguing in front of target youth would be accounted for by the program-targeted changes in communication. Intervention effects were mediated by change in communication, supporting the hypothesis that a dyadic focus on communication could produce changes in important coparenting processes related to ineffective arguing in front of youth. However, there was asymmetry in the way that intervention effects were mediated in that they were obtained for wives but not husbands. Specifically, for wives, program effects were fully mediated through intervention targeted changes in marital communication. In addition, intervention effects on husbands' short-term changes in effective communication and long-term changes in arguing in front of target youth were mediated, in part, by wives' changes in

TABLE 2

Significance of the Indirect Effects on Conflict in Front of the Target Youth Through Communication $(\mathrm{N}=331$ Couples $)$

\begin{tabular}{lccc}
\hline Paths & Total effect & Indirect effect & $\begin{array}{c}\text { The portion of the } \\
\text { variance for } \\
\text { mediator, \% }\end{array}$ \\
\hline $\begin{array}{c}\text { Path 1: Intervention } \rightarrow \text { Communication } \\
\text { (wives) } \rightarrow \text { Observable Conflict (wives) }\end{array}$ & $.127^{* *}[.045 ; .208]$ & $.064^{* *}[.027 ; .102]$ & 50.8 \\
$\begin{array}{c}\text { Path 2: Intervention } \rightarrow \text { Communication } \\
\text { (husbands) } \rightarrow \text { Observable Conflict } \\
\text { (husbands) }\end{array}$ & $.101^{*}[.024 ; .178]$ & $.017[-.008 ; .043]$ & 16.8 \\
\hline
\end{tabular}

Note. The values presented are standardized parameters. Bootstrapping with 1,000 replications.

${ }^{* *} p \leq .01$ (two-tailed test); ${ }^{*} p \leq .05$ (two-tailed test). 
effective communication and co-parenting, respectively. Thus, the intervention appeared to have a more direct effect on wives, and to work in the manner hypothesized. However, effects on husbands appear to be more indirect and dependent on program impact on wives. Even though the total effect of the intervention on change in communication and reduction in arguing in front of target youth was not significantly different for husbands and wives, the examination of mechanism of change indicated that the process of change did not follow the same pattern for husbands and wives. For wives, the process of change was consistent with the hypothesized change model. Improvement in couple communication led to reductions in arguing in front of target youth. For husbands, however, a considerable amount of positive change depended on degree of wife reported change.

The observed pattern of findings suggests potential divergence in the impact of the intervention as a function of gender. In the context of the current program, wives' changes in communication from baseline to posttest may be more pivotal for the couples' long-term experience of arguing in front of target youth than are husbands' changes, with wives' changes leading to changes in both partners' long-term reports. At one level, this result may be seen as somewhat disappointing because the hope was that direct father involvement in the parenting program would create the potential for fathers to play a more pivotal role in the enhancement of co-parenting. The fact that mother reported changes accounted for most of the couples' long-term positive change suggests that this hope was not fully realized, although perhaps the presence of fathers supported mother changes in ways not fully captured in our analyses. Indeed, it may be that presence of fathers enhanced learning outcomes for mothers. Conversely, it may be that wives' reports have somewhat greater validity, allowing changes to be measured more accurately and resulting in more variance accounted for in outcomes. At the same time, the results may suggest the potential to explore additional components that might either build on the key role of mothers in fostering mothers' and fathers' long-term satisfaction with the couples' co-parenting, or conversely introduce new elements in the dyadic focus that might further engage fathers, rippling through to influence aspects of their co-parenting.

One approach that would build on the current investigation would be to examine the impact on co-parenting outcomes for relationship enhancement strategies that are focused on working with one partner only (e.g., Halford, 2011; Wadsworth et al., 2011). Such approaches may have logistical advantages that would make them more readily disseminated and perhaps less expensive. Although such approaches would seem to be at odds with the premise that greater father involvement is critical for enhanced co-parenting outcomes, they are not at odds with the broader expectation that interventions designed to enhance key aspects of the dyadic relationship between spouses have the potential to influence important outcomes in the co-parenting domain. Accordingly, to the extent that a relationship-oriented intervention focused on one partner is able to influence communication patterns in the context of co-parenting for both partners, this might prove to be an attractive option for some families who may be stressed by competing demands and yet are interested in enhancing their co-parenting.

A second approach consistent with the current results would be to expand the dyadic focus to address a broader range of couple activities including support and companionship activities to have a broader impact on the dyadic relationship. A broader focus of this sort might have a greater direct effect on fathers' co-parenting than did the more focused, communication approach. If so, an expanded relational focus might result in changes that would have greater direct effect on fathers' co-parenting, greater effect of the program on fathers' co-parenting via their own changes in response to the intervention, and perhaps greater indirect impact of the intervention on wives via husband changes. In particular, an expanded focus might include greater emphasis on friendship, support, and caring activities in addition to enhanced communication. To 
the extent that incorporation of such activities resulted in both partners receiving more of what they wanted, it could enhance program effects on quality of co-parenting while strengthening the contribution of both partners.

For clinicians, this study offers various implications when working with couples. First, results highlight the benefits of targeting couple communication processes. Short-term improvements in this domain appear to promote later improvements in other aspects of family functioning. Also, as previously noted, mechanisms of change may differ by gender, with communication demonstrating centrality for wives, but other processes may be more central to fostering change in husbands. Finally, when attempting to engage all family members, particularly men, in couples programs, providing sessions in the home environment may warrant consideration.

There are also several limitations in this study that should be addressed in future research. First, it would be desirable to add direct measures of observed interaction change in the home to confirm self-reported change. In the absence of observational data, it is possible that the mediation observed reflects impact on a third variable rather than impact on behavior change. Second, it would be desirable to examine secondary benefits of the intervention program for the couple in terms of health or mental health outcomes to determine if such effects emerge for the parents, potentially enhancing the long-term payoffs of program participation. Third, in keeping with a focus on understanding mechanisms of change in the family, it would be useful to examine impact on parent-child interactions to better understand how changes in fathers' and mothers' dyadic behavior influence interactions with the target child. Fourth, it will be important for future research to examine the impact of key changes in parenting behavior, such as arguments in front of the children, on both internalizing and externalizing child outcomes. Of course, examination of impact on child outcomes will require attention to developmental issues, and so may require using a sample in which the target youth are more homogeneous with regard to age than is the case for the current sample. Conversely, the current sample may allow for examination of interaction of degree of parent change with youth developmental stage. Fifth, future research should address the impact of parenting programs in the presence of contextual stress. In particular, a program designed to more adequately address supportive couple processes in the context of economic stress may have additional potential to prevent the corrosive effect of contextual stress on parenting and boost program efficacy.

In sum, the current results support the potential for marital relationship enhancement focused on communication to produce reductions in the problematic practice of arguing, complaining, and criticizing the partner in front of the children. At the same time, the results suggest several potential ways for the effects to be further enhanced. Mediational analyses are pivotal in identifying both the strengths and the potential weaknesses of intervention strategies. Future research will need to expand the current model to include child outcomes and demonstrate impact on children's long-term well-being.

\section{REFERENCES}

Beach, S. R. H., Hurt, T. R., Fincham, F. D., Franklin, K. J., McNair, L. M., \& Stanley, S. M. (2011). Enhancing marital enrichment through spirituality: Efficacy data for prayer focused relationship enhancement. Psychology of Religion and Spirituality, 3(3), 201-216. doi:10.1037/a0022207.

Black, M. M., Dubowitz, H., \& Starr, R. H. Jr. (1999). African American fathers in low income, urban families: Development, behavior, and home environment of their three-year-old children. Child Development, 70(4), 967-978.

Bradbury, T. N. (1989). Cognition, emotion, and interaction in distressed and nondistressed marriages. Unpublished doctoral dissertation. University of Illinois, Urbana-Champaign. 
Brandon, R. R., Higgins, K., Pierce, T., Tandy, R., \& Sileo, N. (2009). An exploration of the alienation experienced by African American parents from their children's educational environment. Remedial and Special Education, 31(3), 208-222. doi:10.1177/0741932509338350.

Brody, G. H., Chen, Y.-F., Murry, V. M., Ge, X., Simons, R. L., Gibbons, F. X. et al. (2006). Perceived discrimination and the adjustment of African American youths: A five-year longitudinal analysis with contextual moderation effects. Child Development, 77(5), 1170-1189. doi:10.1111/j.1467-8624.2006.00927.x.

Brody, G. H., \& Flor, D. L. (1998). Maternal resources, parenting practices, and child competence in rural, singleparent African American families. Child Development, 69(3), 803-816. doi:10.2307/1132205.

Brody, G. H., Murry, V. M., Kogan, S. M., Gerrard, M., Gibbons, F. X., Molgaard, V. et al. (2006). The Strong African American Families Program: A cluster-randomized prevention trial of long-term effects and a mediational model. Journal of Consulting and Clinical Psychology, 74(2), 356-366. doi:10.1037/0022-006X.74.2.356.

Brody, G. H., Stoneman, Z., Flor, D., \& McCrary, C. (1994). Financial resources, parent psychological functioning, parent co-caregiving, and early adolescent competence in rural two-parent African-American families. Child Development, 65(2), 590-605. doi:10.2307/1131403.

Bzostek, S. H. (2008). Social fathers and child well-being. Journal of Marriage and Family, 70(4), 950-961.

Cohen, D. A., \& Linton, K. L. (1995). Parent participation in an adolescent drug abuse prevention program. Journal of Drug Education, 25(2), 159-169.

Coiro, M. J., \& Emery, R. E. (1998). Do marriage problems affect fathering more than mothering? A quantitative and qualitative review. Clinical Child and Family Psychology Review, 1(1), 23-40.

Coley, R. L. (2003). Daughter-father relationships and adolescent psychosocial functioning in low-income African American families. Journal of Marriage and Family, 65(4), 867-875.

Conger, R. D., Ge, X., Elder, G. H., \& Lorenz, F. O. (1994). Economic stress, coercive family process, and developmental problems of adolescents. Child Development, 65(2), 541-561.

Crane, D. R., \& Mead, D. E. (1980). The Marital Status Inventory: Some preliminary data on an instrument to measure marital dissolution potential. The American Journal of Family Therapy, 8, 31-35.

Cummings, E. M., \& Davies, P. T. (2002). Effects of marital conflict on children: Recent advances and emerging themes in process-oriented research. Journal of Child Psychology and Psychiatry, 43(1), 31-63.

Cummings, E. M., Goeke-Morey, M. C., \& Graham, M. A. (2002). Interparental relations as a dimension of parenting. In M. M. Bristol-Power, J. G. Borkowski, \& S. L. Landesman (Eds.), Parenting and the child's world: Influences on academic, intellectual and socio-emotional development (pp. 251-264). Mahwah, NJ: Lawrence Erlbaum Associates Inc.

Dishion, T. J., Kavanagh, K., Schneiger, A., Nelson, S., \& Kaufman, N. K. (2002). Preventing early adolescent substance use: A family-centered strategy for the public middle school. Prevention Science, 3, 191-201.

Eccles, J. S., Midgely, C., Wigfield, A., Buchanan, C., Reuman, D., Flanagan, C. et al. (1993). Development during adolescence: The impact of stage-environment fit on adolescents' experiences in school and families. American Psychologist, 48, 90-91.

Ge, X., Brody, G. H., Conger, R. D., Simons, R. L., \& Murry, V. M. (2002). Contextual amplification of pubertal transition effects on deviant peer affiliation and externalizing behavior among African American children. Developmental Psychology, 38, 42-54.

Grych, J. H. (2005). Interparental conflict as a risk factor for child maladjustment: Implications for the development of prevention programs. Family Court Review, 43, 97-108. doi:10.1111/j.1744-1617.2005.00010.x.

Halford, W. K. (2011). Marriage and relationship education: What works and how to provide it. New York: Guilford Press.

Hawkins, A. J., Blanchard, V. L., Baldwin, S. A., \& Fawcett, E. B. (2008). Does marriage and relationship education work? A meta-analytic study. Journal of Consulting and Clinical Psychology, 76(5), 723-734. doi:10.1037/ a0012584.

Hawkins, A. J., \& Fackrell, T. A. (2010). Does relationship and marriage education for lower-income couples work? A meta-analytic study of emerging research. Journal of Couple and Relationship Therapy, 9(2), 181191. doi:10.1080/15332691003694927.

Hu, L.-T., \& Bentler, P. M. (1999). Cutoff criteria for fit indexes in covariance structure analysis: Conventional criteria versus new alternatives. Structural Equation Modeling: A Multidisciplinary Journal, 6(1), 1-55. doi:10.1080/10705519909540118.

Hurt, T. R., Beach, S. R. H., Stokes, L. A., Bush, P. L., Sheats, K. J., \& Robinson, S. G. (2012). Engaging Black men in empirically based marriage enrichment programs: Lessons from two focus groups on the ProSAAM project. Cultural Diversity and Ethnic Minority Psychology, 18(3), 312-315. doi:10.1037/a0028697.

Jayakody, R., \& Kalil, A. (2002). Social fathering in low-income, African American families with preschool children. Journal of Marriage and Family, 64(2), 504-516.

Jenkins, N. H., \& Saiz, C. C. (1995). The communication skills test. Unpublished manuscript. University of Denver, Denver, CO. 
Jones, D., Shaffer, A., Forehand, R., Brody, G., \& Armistead, L. P. (2003). Coparent conflict in single motherheaded African american families: Do parenting skills serve as a mediator or moderator of child psychosocial adjustment? Behavior Therapy, 34(2), 259-272. doi:10.1016/S0005-7894(03)80016-3.

Jones, D., Zalot, A., Foster, S., Sterrett, E., \& Chester, C. (2007). A review of childrearing in African American single mother families: The relevance of a coparenting framework. Journal of Child and Family Studies, 16 (5), 671-683.

Jordan, L. C., \& Lewis, M. L. (2005). Paternal relationship quality as a protective factor: Preventing alcohol use among African American adolescents. Journal of Black Psychology, 31, 152-171. doi:10.1177/ 0095798405274881.

Jordan, P., Stanley, S. M., \& Markman, H. J. (1999). Becoming parents: How to strengthen your marriage as your family grows. San Francisco, CA: Jossey-Bass.

Kenny, D. A., Kashy, D. A., \& Cook, W. L. (2006). Dyadic data analysis. New York: Guilford.

Krishnakumar, A., \& Buehler, C. (2000). Interparental conflict and parenting behaviors: A meta-analytic review. Family Relations, 49(1), 25-44. doi:10.2307/585699.

MacCallum, R. C., Browne, M. W., \& Cai, L. (2006). Testing differences between nested covariance structure models: Power analysis and null hypotheses. Psychological Methods, 11, 19-35.

Markman, H. J., Stanley, S. M., \& Blumberg, S. (2010). Fighting for your marriage: A deluxe revised edition of the classic best-seller for enhancing marriage and preventing divorce. San Francisco, CA: Jossey-Bass.

Markman, H. J., Stanley, S. M., Blumberg, S. L., Jenkins, N. H., \& Whiteley, C. (2004). 12 hours to a great marriage: A step-by-step guide for making love last. San Francisco, CA: Jossey-Bass.

Mayhew, K. P., \& Lempers, J. D. (1998). The relation among financial strain, parenting, parent self-esteem, and adolescent self-esteem. The Journal of Early Adolescence, 18(2), 145-172.

Muthen, L. K., \& Muthen, B. O. (2010). Mplus version 6: Base program and combination add-on. Los Angeles, CA: Muthen \& Muthen.

Norton, R. (1983). Measuring marital quality: A critical look at the dependent variable. Journal of Marriage and the Family, 45, 141-151.

Paschall, M. J., Ringwalt, C. L., \& Flewelling, R. L. (2003). Effects of parenting, father absence, and affiliation with delinquent peers on delinquent behavior among African-American male adolescents. Adolescence, 38(149), $15-34$.

Porter, B., \& O'Leary, K. D. (1980). Marital discord and childhood behavior problems. Journal of Abnormal Child Psychology, 8(3), 287-295. doi:10.1007/BF00916376.

Pruett, M. K., Cowan, C. P., Cowan, P. A., \& Pruett, K. (2009). Lessons learned from the Supporting Father Involvement study: A cross-cultural preventive intervention for low-income families with young children. Journal of Social Service Research, 35(2), 163-179.

Roy, K. M., \& Dyson, O. (2010). Making daddies into fathers: Community-based fatherhood programs and the construction of masculinities for low-income African American men. American Journal of Community Psychology, 45(1-2), 139-154.

Salem, D. A., Zimmerman, M. A., \& Notaro, P. C. (1998). Effects of family structure, family process, and father involvement on psychosocial outcomes among African American adolescents. Family Relations: An Interdisciplinary Journal of Applied Family Studies, 47(4), 331-341.

Simmons, R. G., Burgeson, R., Carlton-Ford, S., \& Blyth, D. A. (1987). The impact of cumulative change in early adolescence. Child Development, 58(5), 1220-1234.

Spoth, R., Redmond, C., \& Shin, C. (1998). Direct and indirect latent-variable parenting outcomes of two universal family-focused preventive interventions: Extending a public health-oriented research base. Journal of Consulting and Clinical Psychology, 66(2), 385-399.

Trzcinski, E. (2002). Middle school children's perceptions on welfare and poverty: An exploratory, qualitative study. Journal of Family and Economic Issues, 23(4), 339-359.

Wadsworth, M., Santiago, C., Einhorn, L., Etter, E., Rienks, S., \& Markman, H. (2011). Preliminary efficacy of an intervention to reduce psychosocial stress and improve coping in low-income families. American Journal of Community Psychology, 48(3/4), 257-271. doi:10.1007/s10464-010-9384-z.

Weiss, R. L., \& Cerreto, M. C. (1980). The marital status inventory: Development of a measure of dissolution potential. American Journal of Family Therapy, 8, 80-85.

Whiting, J. B., \& Crane, D. (2003). Distress and divorce: Establishing cutoff scores for the Marital Status Inventory. Contemporary Family Therapy: An International Journal, 25, 195-205.

Wood, R. G., Moore, Q., Clarkwest, A., Killewald, A., \& Monahan, S. (2012). The long-term effects of Building Strong Families: A relationship skills education program for unmarried parents. Washington, DC: Administration for Children and Families, Office of Planning, Research, and Evaluation. Retrieved December 1, 2012, from http://www.acf.hhs.gov/sites/default/files/opre/bsf_36_mo_impact_report.pdf 